\title{
PARTITURA DE GESTOS E AÇÕES NO TEATRO DE MARIONETES ${ }^{1}$
}

Caroline Holanda

RESUMO: Sob a perspectiva de que o teatro de animação possui certos princípios técnicos específicos dessa linguagem, o presente artigo tece considerações sobre a partitura como uma ferramenta de trabalho do ator no teatro de animação, procurando evidenciar alguns modos de utilização na composição da cena.

PALAVRAS-CHAVES: Teatro de Animação, Princípios Técnicos, Partitura de Gestos e Ações.

Ao nos remetermos ao termo partitura, num primeiro instante, a idéia que nos surge é a noção de partitura musical: um sistema de notação através do qual é possível registrar e reproduzir uma obra musical. No teatro, entretanto, partitura não implica necessariamente registro, mas refere-se a um instrumento de criação do ator e/ou encenador para a construção de um esquema objetivo e diretivo, delineando pontos de apoio e referências para o desenvolvimento de seu trabalho, que são ao mesmo tempo físicos e emocionais.

Tais pontos de apoio sustentam sua memória emocional e cinestésica, seu "corpo pensante". São particulares ao ator e não tem em si valor absoluto. Trata-se muitas vezes de imposturas, de lugares de indeterminação, de astúcias de memorizar mentalmente e corporalmente a trajetória do papel e a situação cronotípica do ator. (PAVIS, 2003, p.91)

A partitura como ferramenta de trabalho surge com maior evidência nos trabalhos dos encenadores europeus do século XX, como Stanislávski e Meyerhold, que tinham o ator como componente fundamental do fazer artístico teatral e buscavam o desenvolvimento de teorias de cena e métodos de treinamento para promover uma maior expressividade ao corpo, combatendo a atuação como produto de uma inspiração e atribuindo ao domínio técnico um caminho que, oposto a uma prisão, liberta o ator e encenador para o ato criativo. ${ }^{2}$

1 Artigo publicado no livro TEATRO DE BONECOS: Distintos Olhares sobre Teoria e Prática, sob a organização do Professor Dr. Valmor Beltrame, do Departamento de Artes Cênicas - UDESC.

2 Sobre o conceito de partitura em cada um dos mais importantes encenadores novecentistas ver o trabalho de conclusão de curso de Mônica Siedler (referência na bibliografia). Além das reflexões tecidas, a pesquisa traz em seu anexo a tradução de um importante texto de Patrice Pavis sobre esse assunto. 
Alguns destes encenadores trabalhavam com o conceito de partitura para o ator, outros, como Artaud e Brecht, estenderam o papel da partitura a toda a encenação e muito embora eles a tenham usado como uma metáfora para articular o trabalho do ator ou a encenação, existiram tentativas de registro dessas partituras. No desenvolvimento desse trabalho, elencaremos algumas reflexões acerca do caráter semiográfico da partitura no teatro e suas implicações nessa perspectiva.

$\mathrm{O}$ ator do teatro de marionetes não pode prescindir desses princípios de composição cênica, entretanto, apresenta peculiaridades intrínsecas à linguagem. Há uma idéia equivocada de que o marionetista não é ator, que não cria personagens e não as representa, e tem um trabalho de corpo amputado, concentrado nas mãos. Todavia, não é possível pensar na atuação do ator-animador dissociada de um trabalho psicofísico. O que ocorre, entretanto, é que a animação constitui-se numa linguagem teatral que apresenta peculiaridades. A mais fundamental delas é o fato de que a personagem não se encontra encarnada no corpo do ator como tal, mas em um objeto inerte que necessita do corpo do ator para adquirir vida, como um acoplamento de um objeto que se torna extensão desse corpo. Assim, o objeto inerte é tão somente um objeto, o que o transforma em personagem é a ação dramática, a interpretação do ator estendida a ele diante do espectador. Portanto, na animação de um objeto inanimado é o corpo do ator que atua. Nas palavras de VALMOR BELTRAME,

Animar é transformar o objeto inerte em personagem. O que caracteriza a arte do teatro de animação não é apenas o objeto em si, tampouco seu desenho, forma, peso volume e o material que é construído, embora esses elementos acabem sendo determinantes na animação do espetáculo. É a animação que dá sentido ao objeto e faz com que ele exista e só a ação justifica sua presença na cena. O que o transforma é a ação e a interpretação diante do espectador. (2003, p. 37-38)

O trabalho de animação de objetos é orientado por uma concepção base de que o movimento é elemento fundamental do ato de animar, é o que confere vida ao objeto. Conforme Hubert Japelle "o movimento estabelece uma conexão direta com a nossa atividade psíquica", ou, "o objeto parece vivo porque parece pensar, e parece pensar quando parece estar decidindo por si mesmo.”(JAPELLE apud AMARAL, 1997, p. 86).

Sob o ponto de vista dramático, movimento é o que confere vida a um objeto. Em teatro de animação, movimento é uma ação com intenção. Um objeto 
torna-se animado quando os seus movimentos são, ou parecem ser, intencionais. Essa sua aparente intenção lhe é conferida pelo atormanipulador. Sob os seus impulsos, o objeto "adquire vida". O movimento dos objetos obedece a estímulos internos e externos. Estímulos internos ocorrem quando seu movimento parece intencional - sem intenção não existe animação. Estímulos externos são as condições decorrentes de sua forma. (AMARAL, 2002, p.120)

Contudo uma manipulação de qualidade não pode imprimir no boneco um movimento qualquer. Assim, o ator tem de selecionar, definir e ordenar a seqüência de gestos e ações que qualifiquem a presença da personagem em cena, construindo uma partitura de gestos e ações para o boneco.

Meyerhold atribui grande importância ao movimento, ele realiza estudos para o trabalho do ator a partir da compreensão de alguns fundamentos do movimento, trabalhando com outros dois princípios do teatro que também se aplicam ao teatro de marionetes o da economia de meios e precisão no movimento.

\footnotetext{
O movimento numa representação é o meio de expressão mais poderoso; o papel do movimento cênico é o mais importante de todos os elementos teatrais. Privado da palavra, do figurino, de todos os outros elementos, o teatro continua teatro somente com o ator e sua arte de movimentos. (MEYERHOLD, 1969, p.135)
}

Em Meyerhold o conceito de partitura aparece por meio do que ele denominou de “desenho de movimentos", ou de "desenhos plásticos".

Desse modo, pensar a partitura no teatro de marionetes pode tangenciar três esferas: a partitura da encenação, do ator e da marionete.

A partitura da encenação tenta dar conta do conjunto dos elementos presentes na encenação, buscando criar e visualizar o todo como os diversos instrumentos de uma orquestra. A partitura do ator-bonequeiro será em grande medida resultado da partitura do boneco. Esta, por sua vez, é uma criação do marionetista conjuntamente com o diretor, detalhando a seqüência de movimentos, gestos e ações de cada personagem no espaço e no tempo, em cada cena do espetáculo. Esta partitura tem de se pautar em aspectos como a técnica de animação utilizada; as limitações mecânicas das articulações do boneco e os materiais com os quais foi construído; a coerência com a composição da personagem e a concepção total da encenação; a subpartitura.

A subpartitura é um termo usado por Barba e indica a idéia por trás da ação. São os pontos de apoio, a mobilização interna do ator na instauração de uma personagem que, no 
teatro de marionetes deve ser transferida para o boneco. Segundo Barba, essa subpartitura é constituída de imagens detalhadas ou de regras técnicas, de relatos e perguntas a si mesmo ou de ritmos, de modelos dinâmicos ou de situações vividas ou hipotéticas.” (1994, p.167). Assim, a ação é como o figurino de um boneco de luva: ela seria o vestido e a subpartitura o forro desse vestido ${ }^{3}$.

Entre os bonequeiros brasileiros, a idéia de partitura quando é utilizada na maioria das vezes não é denominada dessa forma. Mas há depoimentos de trabalhos que registram uma grande mudança qualitativa ao trabalhar com esse princípio. O bonequeiro João da Silva, por exemplo, de São Paulo, em seu espetáculo Princípio do Espanto, revela o salto qualitativo que representou a adoção desse instrumento de trabalho. Miguel Velhinho, diretor do grupo carioca PeQuod, ao discorrer sobre seu processo de construção de personagem explicita o uso da partitura de movimento para o ator e o boneco, ainda que não utilize esse termo. Ele conta que o primeiro passo na animação desse boneco é levantar detalhadamente quem é aquele personagem, suas características emocionais, sua história, etc. Em seguida o grupo confecciona o boneco e vai caracterizar no movimento as particularidades dessa personagem. "Tudo parte do humano", ele fala. Antes de montar os movimentos com os bonecos ele monta com os atores e depois vai "decoupando" o movimento e levando para o boneco. Em outras palavras, selecionando ações, gestos e falas, compondo uma partitura para o boneco. ${ }^{4}$

\section{A PARTITURA COMO OBJETO SEMIOGRAFICO}

A utilização da partitura nesse sentido é ainda menos usada na arte do teatro/teatro de bonecos. O registro apresenta dois aspectos de grande importância:

\section{$1 . O$ registro como documento histórico.}

2.O registro como caminho para visualização do trabalho do ator ou encenador e por conseqüência, uma forma de reflexão para criação e recriação de sua obra.

\footnotetext{
3 Para Barba o sub-texto (termo utilizado também por Stanislavski) é uma forma particular de subpartitura. A subpartitura abrange outros aspectos que vão além da intenção ou pensamento não expresso de um personagem, de seu porquê.

4 Depoimento dado em resposta ao questionamento de um dos presentes no lançamento da revista Móinmóin, no VII Festival Internacional de Teatro de Bonecos, ocorrido em Belo Horizonte - MG, em junho de 2006.
} 
Para constituir-se um sistema notacionals são necessários alguns requisitos que Cerri (2003) delineia:

-Da composição dos caracteres: existem os caracteres atômicos - aqueles que compõem a menor partícula do "texto" - e caracteres compostos - aqueles que resultam da combinação de inscrições atômicas. A partir das inscrições atômicas se compõem regras para combinação dos caracteres compostos, já que nem todas as inscrições mescladas constituem um caracter composto. Para ilustração, pensemos nas letras do alfabeto como caracteres atômicos e as palavras inscrições compostas e que, nem todas as combinações de letras originam palavras. A complexificação das combinações variam de um sistema notacional a outro. Na música, os mesmos caracteres podem significar diferentes composições dependendo da clave onde está inscrita.

- Requisitos sintáticos: nenhum signo pode pertencer a mais de um caracter e este por sua vez, necessitam estar separados em classes distintas para que se reduza a margem de erro na identificação dos signos, para que se coloquem sem confundir-se. Um sistema notacional deve apresentar um número de caracteres atômicos finitos e manter uma propriedade essencial, a da equivalência sintática, que implica que os caracteres de uma notação possam ser trocados entre si, sem conseqüências sintáticas (para ilustrar, pensemos nos caracteres do alfabeto).

-Congruência: o termo refere-se à relação de correspondência que deve existir entre um sistema notacional e sua execução.

-Requisitos semânticos: implica na não ambigüidade, isto é, que a relação de congruência entre objetos-referentes e notações-significantes seja invariável e não permita margem à equívocos. Para que não haja ambigüidade a composição dos caracteres e seus aspectos sintáticos devem estar de acordo com os requisitos acima expostos.

Outros requisitos são estabelecidos para que um sistema notacional possa ter uma aplicabilidade prática:

Com os requisitos dos sistemas notacionais, propostos até agora, não se definem ou asseguram um vocabulário e uma gramática adequada. Além do requisito de um conjunto de caracteres atômicos razoavelmente limitado, é preciso estabelecer outros requisitos como os da claridade, legibilidade, duração no tempo, "praticidade" de uso, facilidade de percepção e

5 Cerri (2003) define notação como um universo estruturado de caracteres pertencentes a um esquema simbólico que possibilita, a partir dessa notação, estruturar uma partitura. 
interpretação, subjetividade gráfica para as cópias e facilidade mnemônica para a aprendizagem, rapidez de reprodução e execução e muitos outros. (CERRI, 2003, p.51, tradução nossa)

\section{NOTACÃO E TEATRO}

Em sentido semiográfico, a partitura tem sido mais utilizada pelo encenador que pelo ator. O diretor busca organizar as diversas esferas do espetáculo por meio dos chamados "cadernos de direção". Dado o seu caráter plurilinguístico, o teatro não possui um sistema notacional que englobe as variadas dimensões de um espetáculo. Desse modo tem-se de construir variadas partituras, como por exemplo, cenográficas, cinéticas, luminotécnica, musical, etc. No teatro não existem caracteres sem que estes exijam muitas opções de interpretação, ou seja, são privados de separação e diferenciação semântica delineando um caráter de ambigüidade á linguagem, contrariando os requisitos notacionais outrora comentados. Assim a congruência exige uma correspondência entre os elementos de diferente natureza, isto é, classes de congruência. Nessa perspectiva, um gesto do ator ocorre em harmonia com a notação inserida na partitura da luz, bem como com a partitura cenográfica, por exemplo. Pavis faz referência a essa questão em seu dicionário, num tópico que intitula-se "A Impossível Partitura Cênica":

Se a música dispõe de um sistema muito preciso para notar as partes instrumentais de um trecho, o teatro está longe de ter á sua disposição semelhante metalinguagem capaz de fazer o levantamento sincrônico de todas as artes cênicas, todos os códigos ou todos os sistemas significantes. (1999, p.279)

Ele alude a alguns "puristas" que defendem o texto teatral como um fim em si mesmo e para os quais a encenação não deve ser levada em conta como obra por ser forçosamente falsificadora, atribuindo ao texto o valor de partitura e obra. Ele atribui aos "hieróglifos de ARTAUD ou de GROTOWSKI, os gestus de BRECHT, as ondas rítmicas de STANISLAVSKI e os esquemas biomecânicos de MEYERHOLD” (2003, p. 279) tentativas de composição de uma escritura cênica autônoma, a busca pela criação de uma linguagem de notação cênica.

No teatro de marionetes pouco se tem notícia de partituras escritas. Jean Pierre 
Lescot, marionetista francês que trabalha com sombras, montava uma espécie de storyboard de todo o espetáculo de tal modo que é possível reproduzir seus espetáculos por meio dessa partitura, dado o nível de congruência alcançada. Abaixo a imagem de um storyboard feito por Lescot, que distribui as informações, nesse caso, em texto, imagem e ação.

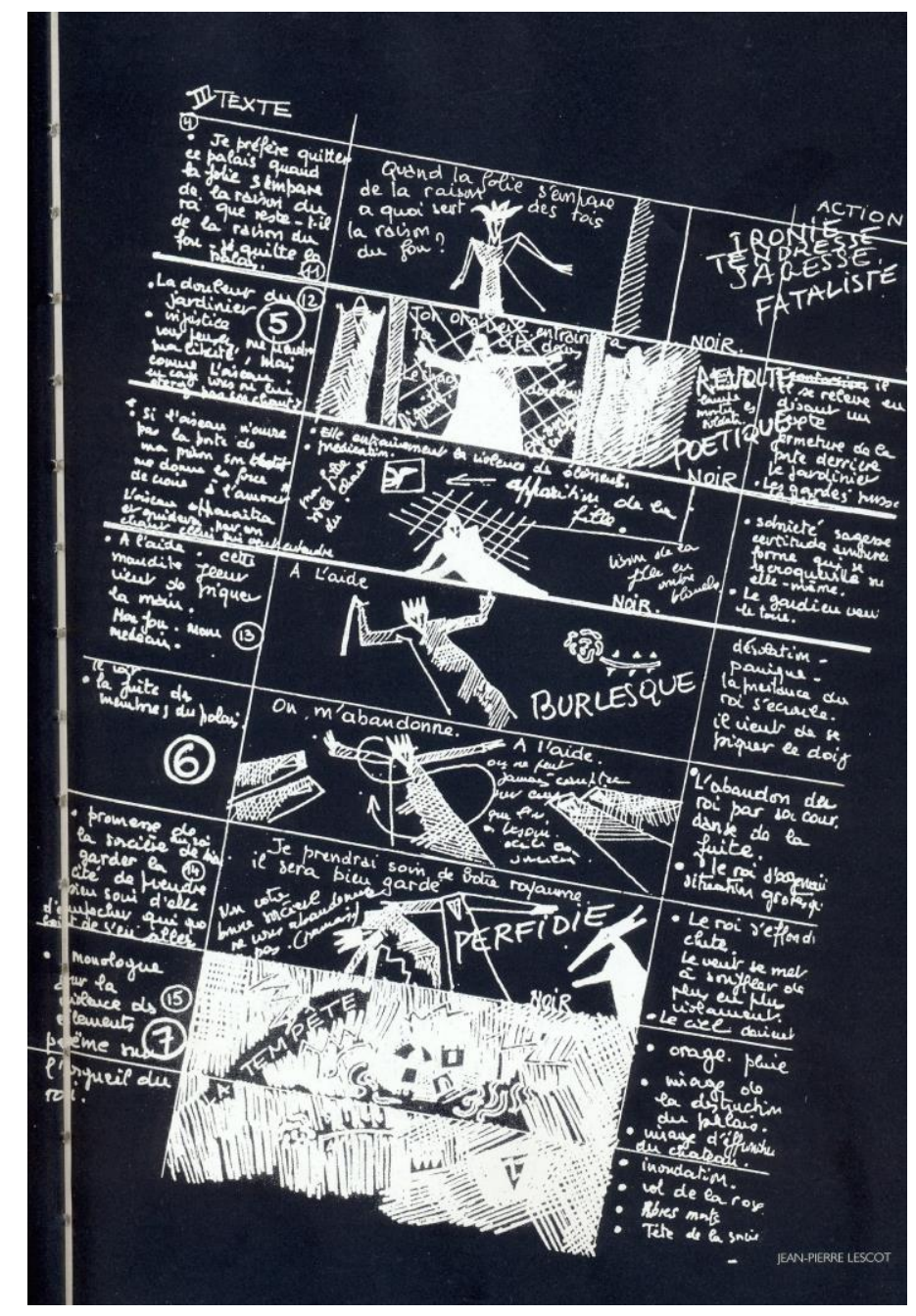

(LESCOT apud REUSCH, s/p, 1997)

O storyboard é uma ferramenta utilizada no cinema e no cinema de animação. Cerri (2003) atribui a esse instrumento (no cinema) um relato que se realiza por meio de desenhos. Para o cinema de animação todavia, o storyboard cumpre um papel mais importante na criação e execução da obra, como esclarece os animadores Whitaker \& Halas (1981), constituindo um momento de planejamento da obra fundamental para essa linguagem que envolve variado número de profissionais . O storyboard tem de apresentar a 
composição de cena, o texto dos personagens, os movimentos de câmera, os planos de cena, dentre outros aspectos que podem variar.

O Grupo Giramundo de Teatro de Bonecos, em conversa no lançamento da revista Móin-móin, no VII Festival Internacional de Teatro de Bonecos, fala sobre o interesse e a opção do grupo em trabalhar entre fronteiras das linguagens artísticas e conta sobre o interesse do grupo pelo campo da dança, com um olhar interessado nas notações de movimento que essa linguagem tem usado como composição e registro de suas obras.

Assim, é perceptível, por meio das conversas com os artistas bonequeiros, a presença da partitura no trabalho que estes desenvolvem. Parece que mais raramente essa partitura se estrutura semiograficamente registrada, mas as conversas apontam que essa coreografia do movimento do objeto e do ator ou essa partitura como orquestração de um espetáculo é uma presença constante no desenvolvimento da arte da animação.

\section{REFERÊNCIAS BIBLIOGRÁFICAS}

AMARAL, Ana Maria. Teatro de animação. São Paulo: Ateliê Editorial, 1997.

AMARAL, Ana Maria. O ator e seus duplos: máscaras, bonecos, objetos . São Paulo: Editora SENAC São Paulo, 2002.

ANDRADE, Milton de. Composição do movimento na partitura do ator-dançarino. Anais Memória Abrace, Florianópolis, v.8, 331-332, out. 2003.

BARBA, Eugenio. A canoa de papel. São Paulo: Hucitec: 1994.

BELTRAME, Valmor. O Trabalho do Ator-bonequeiro. In Revista Nupeart, n.2, Florianópolis: Núcleo Pedagógico de Educação e Arte, 2003.

CERRI, Gabrio Zapelli. La huella creativa. San José, C.R: Editorial de la Universidad de Costa Rica, 2003.

PAVIS, Patrice. Dicionário de Teatro. São Paulo: Perspectiva, 1999.

REUSCH, Rainer. Schattentheater - Band 1 : Autoren + Akteure. Editora EinhornVerlag, 1997.

SIEDLER, Monica. A Partitura Corporal e o Trabalho do Ator: Conceitos e Técnicas Aplicativas na Composição da Cena. Florianópolis, 2003. Trabalho de Conclusão de Curso (Licenciatura em Artes Cênicas) - Departamento de Artes Cênicas: Universidade do Estado de Santa Catarina.

WHITAKER, Harold \& HALAS, John. Timing for animation. Oxford: Focal Press, 2004. 